\title{
Risk factors and obstetric complications of large for gestational age births with adjustments for community effects: results from a new cohort study
}

Shu-Kay Ng${ }^{1}$, Adriana Olog ${ }^{2}$, Anneliese B Spinks ${ }^{3}$, Cate M Cameron ${ }^{1}$, Judy Searle ${ }^{4}$, Rod J McClure (* $^{*}$

\begin{abstract}
Background: High birth weight has serious adverse impacts on chronic health conditions and development in children. This study identifies the social determinants and obstetric complications of high birth weight adjusted for gestational age and baby gender.

Methods: Pregnant women were recruited from three maternity hospitals in South-East Queensland in Australia during antenatal clinic visits. A questionnaire was completed by each participant to elicit information on ecoepidemiological exposures. Perinatal information was extracted from hospital birth records. A hierarchical mixture regression model was used in the analysis to account for the heterogeneity of birth weights and identify risk factors and obstetric complications of births that were large for gestational age. A generalized linear mixed model was used to adjust for (random) "community" effects.

Results: Pre-pregnancy obesity (adjusted $\mathrm{OR}=2.73,95 \% \mathrm{Cl}=1.49-5.01$ ), previous pregnancy (adjusted $\mathrm{OR}=2.03$, $95 \% \mathrm{Cl}=1.08-3.81$ ), and married mothers (adjusted $\mathrm{OR}=1.85,95 \% \mathrm{Cl}=1.00-3.42$ ) were significantly associated with large for gestational age babies. Subsequent complications included the increased need for delivery by caesarean sections or instrumental procedures (adjusted $\mathrm{OR}=1.98,95 \% \mathrm{Cl}=1.10-3.55$ ), resuscitation (adjusted $\mathrm{OR}$ $=2.52,95 \% \mathrm{Cl}=1.33-4.79$ ), and transfer to intensive/special care nursery (adjusted $\mathrm{OR}=3.76,95 \% \mathrm{Cl}=1.89-7.49$ ). Communities associated with a higher proportion of large for gestational age births were identified.

Conclusions: Pre pregnancy obesity is the principal modifiable risk factor for large for gestational age births. Large for gestational age is an important risk factor for the subsequent obstetric complications. The findings improve the evidence-base on which to base preventive interventions to reduce the impact of high birth weight on maternal and child health.
\end{abstract}

\section{Background}

Increased numbers of high birth weight infants $(>4000$ g) and large for gestational age (birth weight above the $90^{\text {th }}$ percentile for gestational age) have been reported in North America and Europe [1-3]. Macrosomia, defined by the American College of Obstetricians and Gynecologists, as birth-weight $>4000$ or $>4500$ g irrespective of gestational age is associated in the literature with numerous perinatal and maternal complications.

\footnotetext{
* Correspondence: Rod.McClure@monash.edu
${ }^{5}$ Monash University Accident Research Centre, Monash University, Victoria,

* Correspondence: Rod.McClure@monash.edu
${ }^{5}$ Monash University Accident Research Centre, Monash University, Victoria, VIC 3800, Australia
}

Macrosomic infants are at an elevated risk of shoulder dystocia and associated brachial plexus injury, perinatal asphyxia, meconium aspiration, hypoglycaemia and fetal death $[4,5]$. Associated maternal complications include prolonged labour, labour augmentation with oxytocins, caesarean delivery, prolonged hospital stay and higher mortality from coronary heart disease for the mother [6-8].

Children born large for gestational age are prone to induce neonatal complications [9] and develop insulin resistance [10], obesity, diabetes and early cardiovascular disease later in life [11-13]. High birth weight has also 
been associated with increased future risk of cancer such as leukemia, breast, prostate and colon cancer $[14,15]$. Large for gestational age births have increased from $9.2 \%$ to $10.8 \%$ in male infants and from $9.1 \%$ to $11 \%$ in female infants from 1990 to 2005 [16].

High birth weight is also associated with subsequent childhood and adult obesity $[12,13,17]$. The long-term chronic disease consequences of childhood overweight or obesity are of serious public health concern [18]. The proportion of overweight or obese children in Australia has been increasing at an accelerating rate since the 1980 's, with obesity increasing 2-4 times, and being overweight increasing by $60-70 \%[19,20]$. The reported prevalence of overweight or obesity in an Australian population is $34 \%$ [21]. The increased prevalence has lead to obesity being recognized as a national health priority risk factor in Australia [22].

The use of risk factor information to identify mothers at risk of having large for gestational age births is an important clinical tool as the accuracy of weight estimation in the third trimester, whether by clinical estimation or ultrasound is poor [23]. Although some causes for large for gestational age births (such as maternal obesity and diabetes) are known, some causes of large for gestational age births are of unknown origin $[9,10]$. Previously identified risk factors in the literature associated with increased birth weight are maternal obesity, multiparity, advanced maternal age, ethnicity, excessive weight gain, marital status, smoking, prolonged labour [24]. However, the extent to which each of these factors influence birth weight is unclear. There remains substantial variation in the literature regarding the strength of association between each of the identified risk characteristics and macrosomia.

In this paper, we aim to refine knowledge of the social determinants of large for gestational age births and assess the subsequent obstetric complications adjusted for gestational age and baby gender, on the basis of the first three phases of a new 'Environments for Healthy Living' birth cohort study using a hierarchical mixture regression model. The identification of modifiable risk factors of large for gestational age births may contribute to the development of public health interventions to reduce the escalating burden resulting from high birth weight in Australia.

\section{Methods}

\section{Study design}

The birth cohort study 'Environments for Healthy Living' was launched in November 2006 to quantify the relationship between social, environmental and behavioural factors and the health and development of children in South East Queensland, Australia. The study area contains an estimated population of over $1,300,000$ people or approximately $4 \%$ of Queensland's population. The study region is markedly heterogeneous with respect to age and socioeconomic distribution [25].

Eligible participants were infants of mothers who gave birth at one of three maternity hospitals (Logan, Gold Coast and The Tweed Hospitals) in South East Queensland between November 2006 and August 2008. All women waiting for third trimester antenatal clinic appointments at each of the locations were approached by research trained midwives, provided with a detailed explanation of the study aims and invited to participate in the study. Written informed consent was obtained for release of hospital perinatal data related to the birth of their child, completion of a participant baseline survey and for individual follow-up. Ethics approval for participant recruitment and follow-up of the 'Environments for Healthy Living' birth cohort was obtained from the Griffith University Ethics Committee (Reference number: MED/16/06/HREC) and the Human Research Ethics review Committees of the three participating public maternity hospitals in the study area (reference numbers: 200652, 2006/096, and 358N).

A questionnaire was completed by each participant to elicit information on demographics, socioeconomic status, family structure and relationship, neighbourhood and community connectedness, maternal smoking and drinking behaviour, and the usage of supplements and recreational substances during pregnancy. Perinatal information was extracted from hospital birth records. The Environments for Healthy Living study is based on an ecological model of causation, which attempts to investigate effective social and economic approaches for improving the health of disadvantaged populations and contributing to overall health and wellbeing of populations. A wide variety of health-related exposures and outcomes are measured at baseline and during subsequent follow-up period. The present research extracts variables collected at baseline under the following ecoepidemiological headings: (1) Demographics; (2) Socioeconomics; (3) Psychological and behavioural; (4) Social network and neighbourhood; (5) Birth procedures; and (6) Neonatal. The first four eco-epidemiological categories are potential risk factors for large for gestational age births. Variables in the last two categories are adopted to assess potential obstetric complications of delivering large for gestational age babies. All these variables are included in the subsequent analyses.

\section{Analytic strategy}

Identification of risk factors for large for gestational age births is usually undertaken using a logistic regression approach with dichotomous outcomes of large for gestational age defined by birth weight percentile for gestational age [26]. The large for gestational age variable is 
usually defined on the basis of local growth charts specific for gender and gestational age [27] and thus the definition of large for gestational age infants is subjective to the reference adopted. As mean birth weight has continuously increased in the United States, Canada, Europe, and Asia [1,2], an up-to-date local reference may not be always available. The adoption of an inappropriate reference can result in misleading inference, with the consequent possibility of invalid findings. Moreover, the logistic regression approach is not able to account for heterogeneity as well as variability of birth weights simultaneously. In this paper, a hierarchical mixture regression model [28] has been adopted to simultaneously account for the heterogeneity of birth weights (via mixture modelling) and adjust for risk factors and complication variables (via logistic regression). A brief description of the mixture modelling approach is presented in the Appendix.

With the hierarchical mixture regression model, a generalized linear mixed model (GLMM) was used to adjust for inter-community variations (via multilevel modelling) [28], where the community is represented in terms of postal area codes of participating mothers. The impacts of communities on the proportion of large for gestational age births are evaluated based on the "predicted" random effects [29]. A positive random (community) effect indicates an increased proportion of large for gestational age births in a community; see the Appendix.

For the mixture regression modelling presented in the Appendix, we first estimated the unknown parameters in the component densities with the adjustment for gestational age and baby gender. Based on the fixed estimated parameters in the component densities, risk factors were then included into the logistic regression function in steps, where each step corresponds to a single category of risk variables detailed in the study design above. Interactions between variables were considered at each step. For each category of risk variables, we performed the analysis included only individuals for which all variables in the category were present. Variables that were significant at $10 \%$ level (two-sided) within each category were entered into the final model for the determination of risk factors on the proportion of large for gestational age births. Obstetric complications of large for gestational age births were then determined by including the complication variables into the final estimated hierarchical mixture regression model via logistic regression.

The proportion of large for gestational age births in each community was calculated by averaging the estimated posterior probability of large for gestational age for all individuals in that community; see the Appendix. The estimated proportion of large for gestational age births was then compared to the unadjusted proportion of large for gestational age births, which was the estimated proportion of large for gestational age births in all regions without adjusting for the risk factors. Communities with more than ten participants and the proportion of large for gestational age births being higher than the unadjusted proportion of large for gestational age births were identified. These communities were associated with a higher than average proportion of large for gestational age births. Their characteristics in twelve pre-determined community profiles were explored based on the 2006 Australian Census of Population and Housing Community Profile data and the matching digital boundary base maps in generic Geographic Information System format [30].

\section{Results}

\section{Sample characteristics}

During the first three recruitment phases of the study (November 2006 to August 2008), the total number of mothers approached was 3321, of whom 1553 women (46.8\%) agreed to participate and 1565 babies have been registered with the study (including twelve sets of twins).

The baseline characteristics of the recruited cohort are displayed in Table 1. The corresponding details of all births in the study region during 2006 are also presented to allow comparisons between cohort participants and the general population. The birth cohort sample did not differ significantly from the general population for maternal age or infant gender (Table $1)$. However, the percentage of infants with low birth weight $(<2500 \mathrm{~g})$ was approximately half that of babies born in the general population, due to the prospective mothers being recruited in the study towards the end of the third trimester. For the same reason, our sample did not include any infants born before 28 weeks gestation, and had a smaller proportion of infants born between 28 and 36 weeks gestation. In addition, the percentage of twins was approximately half of that in the general population, and our sample had a very small proportion of stillbirths. As the low birth weight and low gestational age groups in our sample are not good representatives of the population in general, the group of low birth weights $(39,2.5 \%)$, gestational age less than 37 weeks, and twin pregnancies are excluded from the analysis. There are a total of 1440 singleton babies with complete information on birth weight, gender, and maternal gestational age for the analysis.

\section{Birth weight}

The adjusted mean birth weights at gestational age of 40 weeks for the first subgroup (corresponding to a group of infants of normal birth weight) are $3619 \mathrm{~g}$ 
Table 1 Baseline characteristics of the cohort and comparisons with all births in the study region

\begin{tabular}{|c|c|c|c|}
\hline \multirow[t]{2}{*}{ Characteristics } & \multicolumn{2}{|c|}{ Frequency (percentage ${ }^{a}$ ) } & \multirow{2}{*}{$\begin{array}{c}\text { P- } \\
\text { value }^{c}\end{array}$} \\
\hline & $\begin{array}{c}\text { Birth cohort } \\
\text { sample } \\
\text { (Years 2006 to } \\
\text { 2008) } \\
n=1565\end{array}$ & $\begin{array}{c}\text { Deliveries in } \\
\text { region } \\
\text { (Year }^{\mathbf{b}} \text { 2006) } \\
\mathrm{n}=\mathbf{8 6 0 8}\end{array}$ & \\
\hline \multicolumn{4}{|l|}{ Gender of infant } \\
\hline Male & 764 (49.9\%) & $4462(51.8 \%)$ & 0.079 \\
\hline Female & $782(50.1 \%)$ & $4145(48.2 \%)$ & \\
\hline Missing data & 19 & 0 & \\
\hline \multicolumn{4}{|l|}{ Maternal age } \\
\hline$<20$ years & 87 (5.7\%) & $512(5.9 \%)$ & 0.239 \\
\hline $20-24$ years & $325(21.1 \%)$ & $1608(18.7 \%)$ & \\
\hline $25-29$ years & $424(27.6 \%)$ & $2388(27.7 \%)$ & \\
\hline $30-34$ years & $427(27.8 \%)$ & $2515(29.2 \%)$ & \\
\hline$\geq 35$ years & $274(17.8 \%)$ & $1584(18.4 \%)$ & \\
\hline Missing data & 28 & 0 & \\
\hline \multicolumn{4}{|l|}{ Birth weight } \\
\hline$<2500 \mathrm{~g}$ & $39(2.5 \%)$ & $450(5.5 \%)$ & $<0.0005$ \\
\hline 2500-3999 g & $1266(81.7 \%)$ & $7073(82.2 \%)$ & \\
\hline$\geq 4000 \mathrm{~g}$ & $244(15.8 \%)$ & $1060(12.3 \%)$ & \\
\hline Missing data & 16 & 2 & \\
\hline \multicolumn{4}{|l|}{$\begin{array}{l}\text { Gestational age at } \\
\text { birth }\end{array}$} \\
\hline$<28$ weeks & $0(0.0 \%)$ & $59(0.7 \%)$ & $<0.0005$ \\
\hline 28-36 weeks & $38(2.4 \%)$ & $536(6.2 \%)$ & \\
\hline 37-41 weeks & $1505(97.2 \%)$ & 7963 (92.5\%) & \\
\hline$\geq 42$ weeks & $6(0.4 \%)$ & $45(0.5 \%)$ & \\
\hline Missing data & 16 & 4 & \\
\hline \multicolumn{4}{|l|}{ Plurality } \\
\hline Singleton & $1532(98.5 \%)$ & $8388(97.4 \%)$ & 0.016 \\
\hline Multiple & $24(1.5 \%)$ & $220(2.6 \%)$ & \\
\hline Missing data & 9 & 0 & \\
\hline \multicolumn{4}{|l|}{ Outcome } \\
\hline Live birth & 1554 (99.9\%) & 8547 (99.3\%) & 0.007 \\
\hline Stillbirth & $2(0.1 \%)$ & $61(0.7 \%)$ & \\
\hline Missing data & 9 & 0 & \\
\hline
\end{tabular}

apercentages are calculated based on the available (non-missing) data. ${ }^{b}$ Data for the study region (Logan, Gold Coast, Beaudesert, Tweed) are provided by Queensland Health and New South Wales Health.

'Chi-square test for comparing proportions between birth cohort sample and the general population.

$(95 \% \mathrm{CI}=3580-3659)$ for males and $3488 \mathrm{~g}(95 \% \mathrm{CI}=$ 3451-3524) for females. For the second subgroup (corresponding to a group of large for gestational age newborns), they are $4394 \mathrm{~g}(95 \% \mathrm{CI}=4231-4556)$ and $4249 \mathrm{~g}$ (95\% CI $=4039-4458)$ for males and females, respectively. For comparison, we quote the $90^{\text {th }}$ and $95^{\text {th }}$ percentiles of Australian national birth weights at gestational age of 40 weeks from 1991 to 1994 , which are $4170 \mathrm{~g}$ and $4340 \mathrm{~g}$, respectively, for singleton males, and $4000 \mathrm{~g}$ and $4170 \mathrm{~g}$, respectively, for singleton females [31].

\section{Proximal risk factors}

The adjusted odds ratios of large for gestational age births for each category of risk factors are provided in Table 2. Several demographic (Pre-pregnancy obesity; Previous pregnancy; Marital status), socio-economic (Education level), and behavioural (Maternal smoking) factors have impact on risk of large for gestational age births. These five risk factors were entered into the final mixture model. The final results of determinants for risk of large for gestational age births are presented in Table 3.

There is an increased likelihood to have a large for gestational age baby (adjusted $\mathrm{OR}=2.73,95 \% \mathrm{CI}=$ 1.49-5.01) for mothers who are categorized as obese during pre-pregnancy based on maternal pre-pregnancy BMI (Table 3). The likelihood of having a large for gestational age baby is also increased for mothers who have had a previous pregnancy (adjusted OR $=2.03$, $95 \% \mathrm{CI}=1.08-3.81$ ) and mothers who are married (adjusted OR $=1.85,95 \% \mathrm{CI}=1.00-3.42$ ). For mothers who did not smoke during pregnancy, there was an increased likelihood for giving birth to a large for gestational age baby (adjusted OR $=4.17,95 \% \mathrm{CI}=1.43$ 12.1). The likelihood of having a large for gestational age baby is, however, decreased for mothers who have higher education level, though this result was only marginally significant at the $10 \%$ level. The assessment of subsequent obstetric complications of large for gestational age births is presented in Table 3. It was found that delivery of large for gestational age baby increases the chance of requiring caesarean section or instrumental procedure (adjusted OR $=1.98,95 \% \mathrm{CI}=1.10-3.55$ ). Also, newborns who are large for gestational age have a significantly higher likelihood of needing resuscitation procedures (adjusted OR $=2.52,95 \% \mathrm{CI}=1.33-4.79$ ) and admission to an intensive or special care nursery (adjusted $\mathrm{OR}=3.76,95 \% \mathrm{CI}=1.89-7.49$ ).

\section{Community effect}

The unadjusted estimated proportion of large for gestational age births was $10.3 \%$. We identified nine communities (postal code areas of participating mothers) that are associated with a higher proportion of large for gestational age births. These nine communities (Figure 1) have a higher proportion of mothers who possess some of those identified risk factors for large for gestational age babies. Of substantial importance is the finding that three of the communities (postal areas 2486, 4127 , and 4280) have a large positive community effect (adjusted ORs are ranged from 1.7 to 2.2), that accounts for unknown adverse effects from the community other than those identified risk factors. The twelve pre-determined characteristics of the nine communities are presented in Table 4. Comparing to other communities, 
Table 2 Categories of risk variables and adjusted odd ratios for large for gestational age $(n=1440)$

\begin{tabular}{|c|c|c|}
\hline Variable category & Frequency (percentage ${ }^{\mathrm{a}}$ ) or Mean (SD) & Adjusted odd ratios $(90 \% \mathrm{Cl})$ \\
\hline \multicolumn{3}{|l|}{ Demographics: } \\
\hline Maternal age & $28.90(5.83)$ & $0.96(0.92,1.01)$ \\
\hline Pre-pregnancy (BMI) obesity ${ }^{b}$ & $211(16.1 \%)$ & $2.73^{*}(1.64,4.55)$ \\
\hline Born in Australia & $1039(72.2 \%)$ & $1.55(0.85,2.82)$ \\
\hline Previous pregnancy & $845(58.7 \%)$ & $2.26^{*}(1.32,3.88)$ \\
\hline Married & $732(51.1 \%)$ & $2.33^{*}(1.36,3.99)$ \\
\hline Maternal work status (employed) & $680(47.6 \%)$ & $1.22(0.75,1.97)$ \\
\hline Missing data ${ }^{c}$ & $144(10.0 \%)$ & \\
\hline \multicolumn{3}{|l|}{ Socio-economics: } \\
\hline House owned & $619(43.3 \%)$ & $1.23(0.74,2.02)$ \\
\hline \multicolumn{3}{|l|}{ Mother (education level) } \\
\hline Not complete high school & $281(19.6 \%)$ & $1.12(0.63,1.98)$ \\
\hline Complete high school/TAFE (Reference) & $883(61.5 \%)$ & Reference \\
\hline University degree & $271(18.9 \%)$ & $0.45^{*}(0.20,1.00)$ \\
\hline \multicolumn{3}{|l|}{ Household income } \\
\hline Low $(<\$ 19,999)$ & $81(6.5 \%)$ & $0.27(0.05,1.55)$ \\
\hline Middle $(\$ 20,000-\$ 80,000$, Ref.) & $835(67.5 \%)$ & Reference \\
\hline High $(>\$ 80,000)$ & $322(26.0 \%)$ & $0.99(0.54,1.80)$ \\
\hline Missing data & 209 (14.5\%) & \\
\hline \multicolumn{3}{|l|}{ Psychological/Behavioural: } \\
\hline No smoking during pregnancy & 1100 (76.9\%) & $5.20^{*}(2.12,12.8)$ \\
\hline Frequency of alcohol (at least weekly) & $122(8.5 \%)$ & $0.72(0.28,1.90)$ \\
\hline Vitamin supplements intake ${ }^{d}$ & $1085(75.3 \%)$ & $0.96(0.58,1.58)$ \\
\hline Maternal mental health (very high risk ${ }^{\mathrm{e}}$ ) & $82(5.8 \%)$ & $0.17(0.01,5.13)$ \\
\hline Missing data & $51(3.5 \%)$ & \\
\hline \multicolumn{3}{|l|}{ Social network/Neighbourhood: } \\
\hline Neighbours friendly or very friendly & $975(68.3 \%)$ & $0.89(0.52,1.51)$ \\
\hline Satisfied/very satisfied with community & $1245(86.8 \%)$ & $1.08(0.44,2.67)$ \\
\hline Community felt like home (agree) & $1045(73.3 \%)$ & $1.17(0.61,2.23)$ \\
\hline Get help when need it (agree) & $1021(71.3 \%)$ & $0.93(0.53,1.63)$ \\
\hline Get services need (agree) & $1114(78.3 \%)$ & $0.96(0.51,1.82)$ \\
\hline Feel safe (agree) & $1128(79.3 \%)$ & $1.69(0.75,3.83)$ \\
\hline Active in community (agree) & $306(21.6 \%)$ & $0.93(0.54,1.62)$ \\
\hline Moved home in past 1 year & $632(44.3 \%)$ & $0.65(0.40,1.08)$ \\
\hline Missing data & $46(3.2 \%)$ & \\
\hline
\end{tabular}

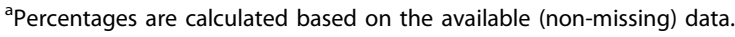

${ }^{\mathrm{b}} \mathrm{BMl}=$ (weight in $\mathrm{kg}$ )/(square of height in meter) $\geq 30$.

${ }^{c}$ Number of individuals with incomplete data within each category of risk variables

${ }^{\mathrm{d}}$ Any of supplements (Iron, Zinc, Calcium, Folic acid, Multi-vitamin, Vitamin C \& E).

eVery high risk based on Kessler scale [45] (Kessler 6 scale >12)

postal areas 4128 and 4129 have higher family incomes, higher labour force participations, but lower percentages of migrants moved in the community within a year. On the other hand, postal areas 4207, 4209, and 4213 have a lower population density but a higher proportion of females doing unpaid domestic work. The postal areas 4223 and 4280 have lower population densities and lower proportions of persons speaking other languages at home. They also have lower proportions of migrants moved in the community within a year. The postal area
2486 is unique; it has a higher percentage of indigenous persons but lower labour force participation.

\section{Discussion}

In this study, two sub-populations of infants were identified, with the first subgroup corresponding to a group of infants of normal birth weight and the second subgroup corresponding to a group of infants with large birth weight adjusted for gestational age and baby gender. We identified several risk factors that significantly 
Table 3 Determinants of risk and obstetric complications of large for gestational age

\begin{tabular}{|c|c|c|}
\hline Variable & Coefficient & $\begin{array}{l}\text { Adjusted odd ratios } \\
(95 \% \mathrm{Cl})\end{array}$ \\
\hline \multicolumn{3}{|c|}{$\begin{array}{l}\text { Determinants of risk of large for gestational age - Demographics, Socio-economics, Psychological and } \\
\text { Behavioural risk factors }(n=1294) \text { : }\end{array}$} \\
\hline Pre-pregnancy (BMI) obesity & 1.006 & $2.73^{*}(1.49,5.01)$ \\
\hline Previous pregnancy & 0.707 & $2.03^{*}(1.08,3.81)$ \\
\hline Married & 0.614 & $1.85^{*}(1.00,3.42)$ \\
\hline Mother education (university degree ${ }^{a}$ ) & -0.897 & $0.41(0.16,1.02)$ \\
\hline No smoking during pregnancy & 1.427 & $4.17^{*}(1.43,12.1)$ \\
\hline \multicolumn{3}{|c|}{ Obstetric complications of large for gestational age - Birth procedures $(n=1235)$ : } \\
\hline \multicolumn{3}{|c|}{ Onset of labour } \\
\hline Spontaneous (Reference) & Reference & \\
\hline Induced & 0.496 & $1.64(0.85,3.18)$ \\
\hline Planned Caesarean section & -0.001 & $1.00(0.42,2.36)$ \\
\hline Presentation (vertex) & -0.356 & $0.70(0.46,1.06)$ \\
\hline Foetal distress & 0.502 & $1.65(0.52,5.30)$ \\
\hline Mode of delivery (Caesarean section or instrumental procedure) & 0.683 & $1.98^{*}(1.10,3.55)$ \\
\hline \multicolumn{3}{|c|}{ Obstetric complications of large for gestational age - Neonatal factors $(n=1282)$ : } \\
\hline APGAR score (5 minutes) & 0.026 & $1.03(0.97,1.09)$ \\
\hline Congenital anomaly & 0.036 & $1.04(0.31,3.42)$ \\
\hline Resuscitation procedures required & 0.925 & $2.52^{*}(1.33,4.79)$ \\
\hline Intensive or special care nursery & 1.324 & $3.76^{*}(1.89,7.49)$ \\
\hline Baby hospital length of stay $>1$ week & 0.595 & $1.81(0.52,6.37)$ \\
\hline
\end{tabular}

aRelative to "no university degree" (not complete high school or complete high school/TAFE)

*Significant results at the $5 \%$ level.

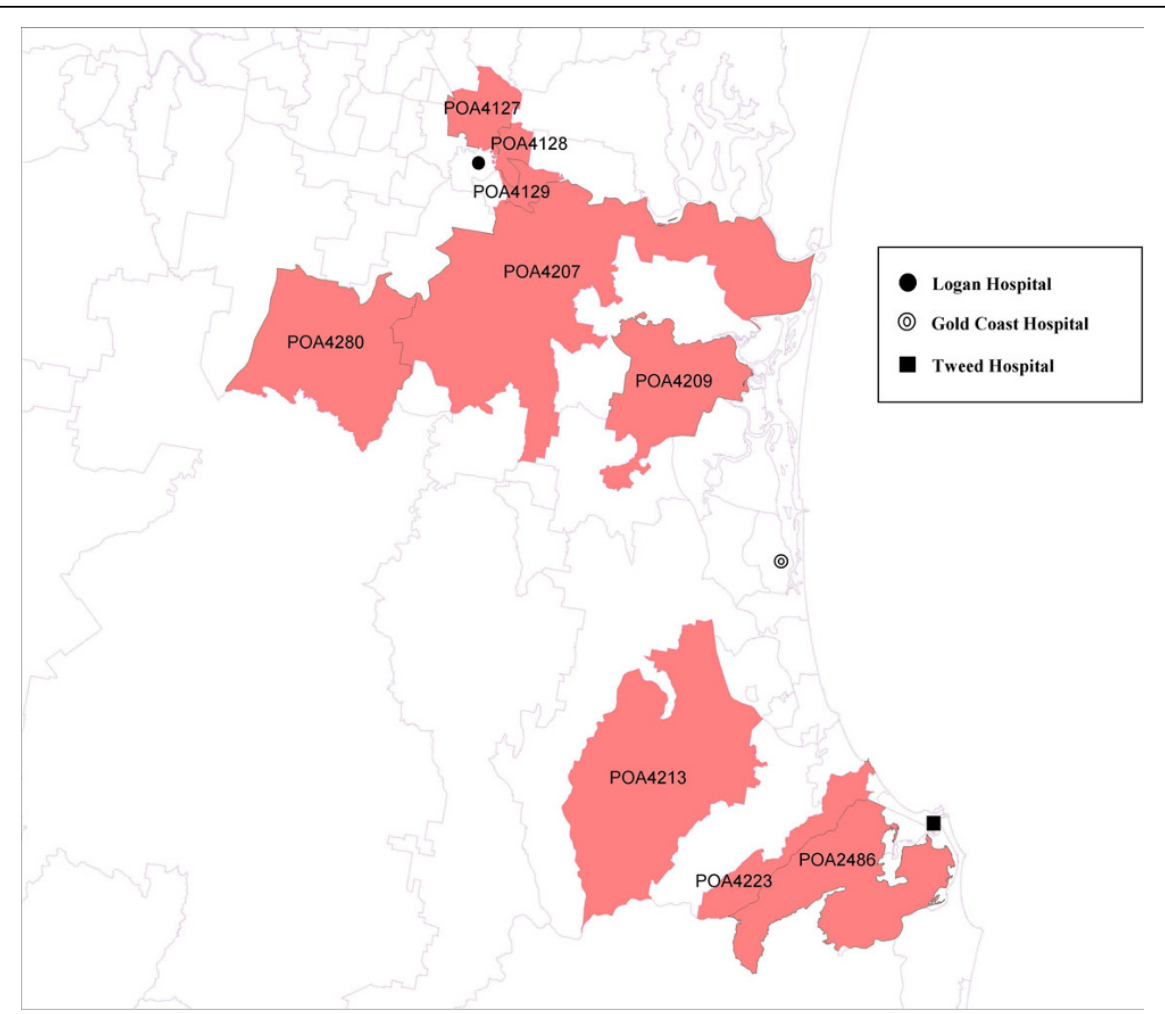

Figure 1 Nine communities, designated by postal area (POA) codes, with a higher proportion of large for gestational age births. 
Table 4 Characteristics of the communities with a high proportion of large for gestational age births

\begin{tabular}{|c|c|c|c|c|c|c|c|c|c|c|c|}
\hline \multirow[t]{2}{*}{ Characteristics } & \multicolumn{9}{|c|}{ 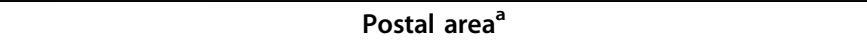 } & \multirow{2}{*}{$\begin{array}{l}\text { Others }^{b} \\
(n=25)\end{array}$} & \multirow[t]{2}{*}{ P-value } \\
\hline & 2486 & 4127 & 4128 & 4129 & 4207 & 4209 & 4213 & 4223 & 4280 & & \\
\hline Population density (person $/ \mathrm{km}^{2}$ ) & $\begin{array}{l}242 \\
(11)\end{array}$ & $\begin{array}{l}727 \\
(16)\end{array}$ & $\begin{array}{c}1357 \\
(23)\end{array}$ & $\begin{array}{l}659 \\
(15)\end{array}$ & $\begin{array}{l}125 \\
(6)\end{array}$ & $\begin{array}{l}196 \\
(9)\end{array}$ & $\begin{array}{c}109 \\
(5)\end{array}$ & $\begin{array}{l}318 \\
(12)\end{array}$ & $\begin{array}{l}92 \\
(3)\end{array}$ & $\begin{array}{c}1109 \\
(21)\end{array}$ & 0.026 \\
\hline Indigenous persons & $\begin{array}{c}3.1 \% \\
(31)\end{array}$ & $\begin{array}{l}1.6 \% \\
(21)\end{array}$ & $\begin{array}{l}0.7 \% \\
(4)\end{array}$ & $\begin{array}{l}1.6 \% \\
(20)\end{array}$ & $\begin{array}{l}2.6 \% \\
(28)\end{array}$ & $\begin{array}{l}1.8 \% \\
(22)\end{array}$ & $\begin{array}{l}1.1 \% \\
(12)\end{array}$ & $\begin{array}{l}1.6 \% \\
(19)\end{array}$ & $\begin{array}{l}1.8 \% \\
(23)\end{array}$ & $\begin{array}{l}1.3 \% \\
(15)\end{array}$ & 0.391 \\
\hline Other language spoken (home) & $\begin{array}{l}3.2 \% \\
\text { (3) }\end{array}$ & $\begin{array}{l}11 \% \\
(25)\end{array}$ & $\begin{array}{c}7.9 \% \\
(19)\end{array}$ & $\begin{array}{l}6.5 \% \\
(16)\end{array}$ & $\begin{array}{l}5.8 \% \\
(11)\end{array}$ & $\begin{array}{l}5.5 \% \\
(10)\end{array}$ & $\begin{array}{l}6.1 \% \\
(12)\end{array}$ & $\begin{array}{c}3.4 \% \\
(4)\end{array}$ & $\begin{array}{c}3.6 \% \\
(5)\end{array}$ & $\begin{array}{l}9.3 \% \\
(21)\end{array}$ & 0.042 \\
\hline Family income (\$/week) & $\begin{array}{l}921 \\
(3)\end{array}$ & $\begin{array}{c}1212 \\
(27)\end{array}$ & $\begin{array}{l}1412 \\
(34)\end{array}$ & $\begin{array}{l}1229 \\
(29)\end{array}$ & $\begin{array}{l}1107 \\
(15)\end{array}$ & $\begin{array}{c}1210 \\
(26)\end{array}$ & $\begin{array}{l}1181 \\
(24)\end{array}$ & $\begin{array}{c}1110 \\
(16)\end{array}$ & $\begin{array}{c}1198 \\
(25)\end{array}$ & $\begin{array}{l}1095 \\
(13.5)\end{array}$ & 0.110 \\
\hline Household size (person) & $\begin{array}{c}2.4 \\
(9.5)\end{array}$ & $\begin{array}{c}2.7 \\
(17)\end{array}$ & $\begin{array}{c}3.0 \\
(29)\end{array}$ & $\begin{array}{c}2.9 \\
(25)\end{array}$ & $\begin{array}{c}2.7 \\
(17)\end{array}$ & $\begin{array}{c}3.0 \\
(29)\end{array}$ & $\begin{array}{c}3.0 \\
(29)\end{array}$ & $\begin{array}{c}2.5 \\
(11)\end{array}$ & $\begin{array}{c}3.2 \\
(34)\end{array}$ & $\begin{array}{c}2.7 \\
(17)\end{array}$ & 0.105 \\
\hline Married persons & $\begin{array}{l}54 \% \\
(28)\end{array}$ & $\begin{array}{l}48 \% \\
(15)\end{array}$ & $\begin{array}{l}55 \% \\
(29)\end{array}$ & $\begin{array}{l}52 \% \\
(23)\end{array}$ & $\begin{array}{l}48 \% \\
(14)\end{array}$ & $\begin{array}{l}50 \% \\
(18)\end{array}$ & $\begin{array}{l}56 \% \\
(31)\end{array}$ & $\begin{array}{l}50 \% \\
(21)\end{array}$ & $\begin{array}{l}58 \% \\
(32)\end{array}$ & $\begin{array}{l}47 \% \\
(13)\end{array}$ & 0.039 \\
\hline Volunteer & $\begin{array}{l}15 \% \\
(27)\end{array}$ & $\begin{array}{l}15 \% \\
(28)\end{array}$ & $\begin{array}{l}16 \% \\
(29)\end{array}$ & $\begin{array}{l}14 \% \\
(18)\end{array}$ & $\begin{array}{l}14 \% \\
(23)\end{array}$ & $\begin{array}{l}13 \% \\
(11)\end{array}$ & $\begin{array}{l}18 \% \\
(33)\end{array}$ & $\begin{array}{l}15 \% \\
(26)\end{array}$ & $\begin{array}{l}15 \% \\
(24)\end{array}$ & $\begin{array}{l}13 \% \\
(14)\end{array}$ & 0.017 \\
\hline Unpaid domestic work (> 5 hours - females) & $\begin{array}{l}73 \% \\
(28)\end{array}$ & $\begin{array}{l}69 \% \\
(20)\end{array}$ & $\begin{array}{l}71 \% \\
(25)\end{array}$ & $\begin{array}{l}72 \% \\
(26)\end{array}$ & $\begin{array}{l}71 \% \\
(24)\end{array}$ & $\begin{array}{l}76 \% \\
(33)\end{array}$ & $\begin{array}{l}71 \% \\
(23)\end{array}$ & $\begin{array}{l}64 \% \\
(13)\end{array}$ & $\begin{array}{l}77 \% \\
(34)\end{array}$ & $\begin{array}{l}65 \% \\
(14)\end{array}$ & 0.008 \\
\hline Age 20-39 ever born & $\begin{array}{l}66 \% \\
(27)\end{array}$ & $\begin{array}{l}55 \% \\
(13)\end{array}$ & $\begin{array}{l}58 \% \\
(17)\end{array}$ & $\begin{array}{l}59 \% \\
(18)\end{array}$ & $\begin{array}{l}66 \% \\
(28)\end{array}$ & $\begin{array}{l}65 \% \\
(26)\end{array}$ & $\begin{array}{l}63 \% \\
(23)\end{array}$ & $\begin{array}{l}57 \% \\
(16)\end{array}$ & $\begin{array}{l}73 \% \\
(34)\end{array}$ & $\begin{array}{l}55 \% \\
(14)\end{array}$ & 0.086 \\
\hline One-parent family with children $<15$ & $\begin{array}{c}9.4 \% \\
(17)\end{array}$ & $\begin{array}{l}11 \% \\
(26)\end{array}$ & $\begin{array}{c}7.5 \% \\
(5)\end{array}$ & $\begin{array}{l}11 \% \\
(24)\end{array}$ & $\begin{array}{l}12 \% \\
(27)\end{array}$ & $\begin{array}{l}12 \% \\
(29)\end{array}$ & $\begin{array}{c}9.3 \% \\
(15)\end{array}$ & $\begin{array}{c}9.3 \% \\
(16)\end{array}$ & $\begin{array}{c}8.0 \% \\
(6)\end{array}$ & $\begin{array}{c}9.6 \% \\
(18)\end{array}$ & 0.785 \\
\hline Labour force participation & $\begin{array}{l}48 \% \\
(2)\end{array}$ & $\begin{array}{l}68 \% \\
(28)\end{array}$ & $\begin{array}{l}74 \% \\
(34)\end{array}$ & $\begin{array}{l}70 \% \\
\text { (31) }\end{array}$ & $\begin{array}{l}62 \% \\
(17)\end{array}$ & $\begin{array}{l}72 \% \\
(33)\end{array}$ & $\begin{array}{l}67 \% \\
(25)\end{array}$ & $\begin{array}{l}59 \% \\
(12)\end{array}$ & $\begin{array}{l}67 \% \\
(26)\end{array}$ & $\begin{array}{l}61 \% \\
(15)\end{array}$ & 0.051 \\
\hline Migrant lived at different address 1 year ago & $\begin{array}{c}16 \% \\
(3)\end{array}$ & $\begin{array}{l}17 \% \\
(11)\end{array}$ & $\begin{array}{c}16 \% \\
(6)\end{array}$ & $\begin{array}{c}17 \% \\
(8)\end{array}$ & $\begin{array}{l}17 \% \\
(12)\end{array}$ & $\begin{array}{l}38 \% \\
(34)\end{array}$ & $\begin{array}{c}17 \% \\
(9)\end{array}$ & $\begin{array}{c}16 \% \\
(5)\end{array}$ & $\begin{array}{c}15 \% \\
(1)\end{array}$ & $\begin{array}{l}20 \% \\
(21)\end{array}$ & 0.008 \\
\hline
\end{tabular}

avalues in parentheses are the rankings am ong the total of 34 communities.

${ }^{b}$ Median values (ranks) are presented among the 25 other communities.

${ }^{c}$ Mann-Whitney test for comparing medians between the nine communities and the others.

increase the chance of having a large for gestational age baby. The findings improve the evidence-base regarding determinants and obstetric complications involving large for gestational age births. High maternal pre-pregnancy BMI has been shown to be related to high birth weight $[2,3,32]$. The association with parity, maternal age and region of birth was recently shown [16]. Our research findings indicate the adverse effect of maternal smoking on birth weights [3] and support previously reported results that reduced smoking prevalence among pregnant women partly explains the temporal increase in proportion of large for gestational age births [2,3]. Similar findings on the association between maternal smoking and low birth weight are demonstrated in the recent cohort studies conducted in Australia [33] and the UK [34]. Our results also confirm that the delivery of a large for gestational age infant is associated with an increased risk of obstetric complications such as caesarean delivery or instrumental delivery for mothers and the needs of resuscitation procedure or intensive/special care nursery for infants $[35,36]$.

The identification of risk factors that are associated with large for gestational age infants has important public health implications. In the short-term, it is essential to target those pregnancies that have a high risk of having a large for gestational age infant and concomitant increased likelihood of obstetric complications. The large for gestational age infants will also have a higher risk of complications in the immediate post-delivery period. Hence they will require more intensive monitoring in the newborn nursery or neonatal intensive care unit [9]. There has been evidence that large for gestational age infants may have long-term health issues in addition to the short-term health complications mentioned above. These include an increased risk of suffering chronic diseases later in life such as diabetes, hypertension, and asthma.

We have identified nine communities that have a higher proportion of large for gestational age births. These communities have certain distinguishable characteristics from other communities in the study. They tend to have a higher proportion of females doing unpaid domestic work (except postal area 4223) but a lower proportion of migrants moving in the communities (except postal area 4209). Of substantial importance is the finding that three of the communities had a large positive community effect even after controlling for identified risk factors. While these findings will have the potential to pinpoint where improvements can be made within the community to reduce the impact of 
high birth weight on chronic health conditions and development in children, further validation on the findings are required when more data become available. The fourth-recruitment phase of the Environments for Healthy Living study has been completed and subsequent recruitment is scheduled for future years. This new birth cohort will help targeting interventions to reduce the escalating burden resulting from high birthweight in Australia. It will also enhance the power to explore further the ecological determinants of large birth-weight and confirm research findings in other populations worldwide.

\section{Strengths and limitations}

In this study, the mixture model assumed that the observed birth weights came from a population that consisted of two components corresponding to the appropriate for gestational age and large for gestational age subgroups. Thus we circumvented a major limitation in previous research in that the mixture modelling approach requires no prehoc threshold [37] to define large for gestational age infants. In contrast to the logistic regression approach that works on dichotomous outcomes of large for gestational age, the mixture modelling method attempts to model directly the birth weights, which are more informative relative to dichotomized outcomes for examining effects of risk factors. Another limitation of the logistic regression approach is that a pre-defined cutoff point for large for gestational age offers only a 'hard' classification of infants to large for gestational age and non-large for gestational age subgroups. This means that the estimated effects of the risk factors will be biased when there are substantially overlapping subgroups. The mixture modelling approach, on the other hand, offers a probabilistic classification of infants in the estimation of unknown parameters, and hence will provide less biased estimation of effect sizes [38].

Given there was complete follow up of subjects between the antenatal ascertainment of explanatory variables and the birth weight and obstetric outcomes the internal validity of the project is strong. The external validity of the results may be compromised by the sample recruitment method that did not engage women who are at risk for delivering babies with low birth weight. Similarly, women using private maternity services (normally those from higher socioeconomic backgrounds) and those with high risk pregnancies referred to specialist care are not captured in the sample. These shortcomings have been addressed in the analysis as described in the methods section by eliminating the group of low birth weights or gestational age smaller than 37 weeks.

In the analysis, we did not include maternal morbidities such as diabetes and hypertension as this information was not available for approximately $30 \%$ of the cohort due to differences in hospital perinatal data collection. As the national prevalence of these maternal co-morbidities are generally quite low (such as, $4.6 \%$ for gestational diabetes [39]), the number of women in our study sample who would have been affected would have been quite small. The association of diabetes and large birth weight has been demonstrated in previous cohort studies $[9,10]$. Moreover, it has been shown that weight gain during pregnancy is also related to large birth weight $[40,41]$. As this information was not available for approximately $55 \%$ of the cohort, it was not possible to perform multivariate analysis of large for gestational age births and potential risk factors with the inclusion of the weight gain during pregnancy without inducing serious bias in the estimation of adjusted odd ratios.

\section{Conclusions}

Pre pregnancy obesity is the principal modifiable risk factor for large for gestational age births. Large for gestational age is an important risk factor for the subsequent obstetric complications. The findings from this new cohort study in Australia improve the evidencebase on which to base preventive interventions to reduce the impact of high birth weight on maternal and child health, and confirm research findings in other populations worldwide.

\section{Further study}

With the Environments for Healthy Living study, followup routinely occurs when each child reaches 1 and 3 years of age. Participating mothers are mailed a questionnaire eliciting details on eco-epidemiological exposures and infant health and developmental outcomes including chronic markers for asthma, cardiovascular disease, and diabetes. In this research, 104 out of 1440 infants are classified as large for gestational age using the mixture modelling approach. Further study will focus on the comparisons of health and developmental issues between this group of children and the other who are not born large for gestational age. This research will improve the evidence base for the long-term health consequences of large for gestational age infants. Future data linkage with Medicare and related health data will also allow identification of health outcomes in this cohort. The longitudinal nature of the Environments for Healthy Living study has the advantage of being able to identify health and development issues in children in their early part of the life course, implement interventions that may minimize obesity problems among children and measure the long-term chronic disease problems in this group. Further research will compare maternal post-pregnancy weight retention between these two groups, as there is evidence that women retain their 
weight post-pregnancy have an elevated risk of entering their next pregnancy either overweight or obese $[16,42]$.

\section{Appendix: Hierarchical mixture regression modelling}

Let $y_{i j}$ denote the baby birth-weight of the $j$ th individual living in the $i$ th community. With the mixture framework, the observed birth weights are assumed to have come from a mixture of two groups (corresponding to the normal and large for gestational age groups) in some unknown proportions that sum to one [38]. A two-component hierarchical-mixture-regression model is represented by

$$
f\left(y_{i j}, x_{i j}, x_{i j}^{\prime}\right)=\left(1-\pi\left(x_{i j}^{\prime}\right)\right) \phi_{1}\left(y_{i j}, x_{i j}\right)+\pi\left(x_{i j}^{\prime}\right) \phi_{2}\left(y_{i j}, x_{i j}\right),
$$

where $\pi\left(x_{i j}^{\prime}\right) \quad$ denotes the probability of the $j$ th individual belonging to the second component corresponding to the subgroup of large for gestational age and $\varphi_{k}$ $\left(y_{i j}, x_{i j}\right)$ is the $k$ th component-density function $(k=1,2)$. The proportion $\pi$ is specified as a logistic function of $x_{i j}$,

$$
\pi\left(x_{i j}^{\prime}\right)=\frac{\exp \left(a+b^{T} x_{i j}^{\prime}+U_{i}\right)}{1+\exp \left(a+b^{T} x_{i j}^{\prime}+U_{i}\right)},
$$

where $x_{i j}^{\prime}$ is a vector of risk factors or complication variables associated with $y_{i j}$ and $U_{i}$ represents the unobservable random effect due to the $i$ th community affecting on the proportion $\pi$. These (random) community effects are taken to be normally distributed with zero mean and variance $\lambda$ [28]. A positive random effect $U_{i}$ indicates an increased proportion of large for gestational age births in a community. It is further assumed that the component densities are normally distributed with a common variance $\sigma^{2}[38]$, and the mean is expressed in terms of $x_{i j}$ corresponding to the variables of gestational age and baby gender. The posterior probability of a large for gestational age birth for the $j$ th individual in the $i$ th community is given by $\tau_{i j}=\pi\left(x_{i j}^{\prime}\right) \phi_{2}\left(y_{i j}, x_{i j}\right) / f\left(y_{i j}, x_{i j}, x_{i j}^{\prime}\right)$. Let $n_{i}$ be the number of participants in the $i$ th community, the proportion of large for gestational age births in the $i$ th community is given by the averaged posterior probability $\sum_{i} \tau_{i j} / n_{i}$. The unknown parameters are estimated using the GLMM approach [28] via the expectation-maximization (EM) algorithm [43]. In particular, the posterior probabilities are computed based on current estimates of model parameters; they lie between zero and one and offer a probabilistic classification of infants with respect to the normal and large for gestational age groups; see, for example, [44]. Model selection and goodness-of-fit can be assessed based on information criteria or the likelihood-ratio test statistic [28]. A Fortran program for the estimation of model parameters is available on request from the first author.

\begin{abstract}
Acknowledgements
The authors wish to thank the Editor and three referees for helpful comments on the paper. The authors are grateful to Queensland Health and New South Wales Health for providing the birth data in the study region during 2006, which allows comparisons between cohort participants and the general population. The authors also thank Rani Scott, Ryan Thwaites and Sunghwa O'Mahony for managing the recruitment and databases of the Environments for Healthy Living birth cohort study. We gratefully acknowledge the hospital antenatal and birth suite midwives of the participating hospitals for their valuable contributions to the study. The study is currently funded by Griffith University. Dr Spinks and Dr Cameron were supported by a Public Health Fellowship (ID 428253 and ID 428254 respectively) from the National Health and Medical Research Council, Australia.
\end{abstract}

\section{Author details}

${ }^{1}$ School of Medicine, Griffith University (Logan Campus), Meadowbrook, QLD 4131, Australia. ${ }^{2}$ Department of Obstetrics and Gynaecology, Gold Coast Hospital, Australia. ${ }^{3}$ Commonwealth Scientific \& Industrial Research Organisation, Australia. ${ }^{4}$ Health Workforce Division, Department of Health \& Ageing, Australia. ${ }^{5}$ Monash University Accident Research Centre, Monash University, Victoria, VIC 3800, Australia.

\section{Authors' contributions}

SN originated the research, led the design and implementation of mixture modelling, conducted the statistical analyses, and led the writing of the article. AO advised on the obesity, obstetrics, and gynecology aspects of the study. AS, CC, JS, and RM originated the Environments for Healthy Living study and supervised all aspects of its implementation. All authors assisted with conceptualizing ideas, interpreted research findings, and contributed to the writing of the article. All authors read and approved the final manuscript.

\section{Competing interests}

The authors declare that they have no competing interests.

Received: 6 April 2010 Accepted: 6 August 2010

Published: 6 August 2010

\section{References}

1. Ananth CV, Wen SW: Trends in fetal growth among singleton gestations in the United States and Canada, 1985 through 1998. Semin Perinatol 2002, 26:260-267.

2. Kramer MS, Morin I, Yang H, Platt RW, Usher R, McNamara $H$, et al: Why are babies getting bigger? Temporal trends in fetal growth and its determinants. J Pediatr 2002, 141:538-542.

3. Surkan PJ, Hsieh CC, Johansson ALV, Dickman PW, Cnattingius S: Reasons for increasing trends in large for gestational age births. Obstet Gynecol 2004, 104:720-726.

4. Boulet SL, Alexander GR, Hamisu MS, Pass MA: Macrosomic births in the United States: Determinants, Outcomes and proposed grades of risk. Am J Obstet Gynecol 2003, 188:1372-1378.

5. Raio L, Ghezzi F, Di Naro E, Buttarelli M, Franchi M, Durig P, Bruhwiler H: Perinatal outcome of foetuses with a birthweight greater than $4500 \mathrm{~g}$ : an analysis of 3356 cases. Eur J Obstet Gynecol Reprod Biol 2003, 109:160-165.

6. American College of Obstetricians \& Gynecologists: Fetal macrosomia, ACOG practice bulletin, no.22 Washington, ACOG 2000.

7. Friedlander Y, Paltiel O, Manor O, Deutsch L, Yanetz R, Calderon R, et al: Birthweight of offspring and mortality of parents: The Jerusalem Perinatal Study Cohort. Ann Epidemiol 2007, 17:914-922.

8. Stotland NE, Caughey AB, Breed EM, Escobar GJ: Risk factors and obstetrics complications associated with macrosomia. Int J Gynecol Obstet 2004, 87:220-226.

9. Das UG, Sysyn GD: Abnormal fetal growth: intrauterine growth retardation, small for gestational age, large for gestational age. Pediatr Clin N Am 2004, 51:639-654. 
10. Giapros V, Evagelidou E, Challa A, Kiortsis D, Drougia A, Andronikou S: Serum adiponectin and leptin levels and insulin resistance in children born large for gestational age are affected by the degree of overweight. Clin Endocrinology 2007, 66:353-359.

11. Boney CM, Verma A, Tucker R, Vohr BR: Metabolic syndrome in childhood: association with birth weight, maternal obesity, and gestational diabetes mellitus. Pediatrics 2005, 115:290-296.

12. Dietz WH: Overweight in childhood and adolescence. N Engl J Med 2004, 350:855-857.

13. Hediger M, Overpeck M, McGlynn A, Kuczmarski R, Maurer K, Davis W: Growth and fatness at three to six years of age of children born smallor large-for gestational age. Pediatrics 1999, 104:33-39.

14. Ross JA: High birthweight and Cancer: evidence and implications. Cancer Epidemiol Biomarkers Prev 2006, 15:1-2.

15. Ahlgren M, Wohlfahrt J, Olsen LW, Sorensen TIA, Melbye M: Birth weight and risk of cancer. Cancer 2007, 110:412-419.

16. Hadfield RM, Lain SJ, Simpson JM, Ford JB, Raynes-Greenow CH, Morris JM, Roberts CL: Are babies getting bigger? An analysis of birthweight trends in New South Wales, 1990-2005. Med J Aust 2009, 190:312-315.

17. Kleiser C, Rosario AS, Mensink G, Prinz-Langenohl R, Kurth B: Potential determinants of obesity among children and adolescents in Germany: results from the cross-sectional KiGGS study. BMC Public Health 2009, 9:46.

18. Srinivasan $S R$, Myers $L$, Berenson GS: Predictability of childhood adiposity and insulin for developing insulin resistance syndrome (syndrome $\mathrm{X}$ ) in young adulthood. Diabetes 2002, 51:204-209.

19. Australian Institute of Health and Welfare (AlHW): A rising epidemic: obesity in Australian children and adolescents Canberra, AlHW 2004 [http://www. aihw.gov.au/riskfactors/data_briefing_no_2.pdf], (Accessed November 18, 2009)

20. Magarey AM, Daniels LA, Boulton TJC: Prevalence of overweight and obesity in Australian children and adolescents: reassessment of 1985 and 1995 data against new standard international definitions. Med J Aust 2001, 174:561-564

21. Callaway LK, Prins JB, Chang AM, Mclntyre HD: The prevalence and impact of overweight and obesity in an Australian obstetric population. Med J Aust 2006, 184:56-59.

22. Obesity Working Group of the National Preventative Health Taskforce: Technical Report No 1: Obesity in Australia: a need for urgent action Canberra, Commonwealth of Australia 2008.

23. Orskou J, Kesmodel U, Henriksen TB, Secher NJ: An increasing proportion of infants weighting more than $4000 \mathrm{~g}$ at birth. Acta Obstet Gynecol Scand 2001, 80:931-936.

24. Langer O: Fetal macrosomia: Etiologic factors. Clin Obstet Gynecol 2000 43:283-297.

25. Queensland Health: Southern Area Health Service Profile Brisbane, Queensland Government 2007.

26. Caulfield LE, Stoltzfus RJ, Witter FR: Implications of the Institute of Medicine weight gain recommendations for preventing adverse pregnancy outcomes in Black and White women. Am J Public Health 1998, 88:1168-1174.

27. Georgieff MK: Assessment of large and small-for-gestational-age newborn-infants using growth-curves. Pediatric Annals 1995, 24:599-607.

28. Yau KKW, Lee $\mathrm{AH}$ : Finite mixture regression model with random effects: application to neonatal hospital length of stay. Comput Stat Data Anal 2003, 41:359-366.

29. Ng SK, McLachlan GJ: Extension of mixture-of-experts networks for binary classification of hierarchical data. Artif Intell Med 2007, 41:57-67.

30. Australian Bureau of Statistics: The 2006 Census of Population and Housing Community Profile data. 2006 (Census datapacks 2006) Canberra, Commonwealth of Australia 2007.

31. Roberts $C L$, Lancaster PAL: Australian national birthweight percentiles by gestational age. Med J Aust 1999, 170:114-118.

32. Doherty DA, Magann EF, Francis J, Morrison JC, Newnham JP: Prepregnancy body mass index and pregnancy outcomes. Int J Gynecol Obes 2006, 95:242-247.

33. Panaretto $K$, Lee $H$, Mitchell $M$, Larkins $S$, Manessis $V$, Buettner $P$, Watson D: Risk factors for preterm, low birth weight and small for gestational age birth in urban Aboriginal and Torres Strait Islander women in Townsville. Aust N Z J Public Health 2006, 30:163-170.
34. Ward C, Lewis $\mathrm{S}$, Coleman T: Prevalence of maternal smoking and environmental tobacco smoke exposure during pregnancy and impact on birth weight: retrospective study using Millennium Cohort. $B M C$ Public Health 2007, 7:81.

35. Oral E, Cagdas A, Gezer A, Kaleli S, Aydinli K, Ocer F: Perinatal and maternal outcomes of fetal macrosomia. Eur J Obstet Gynecol Reprod Biol 2001, 99:167-171.

36. Meshari AA, De Silva S, Rahman I: Fetal macrosomia-maternal risks and fetal outcome. Int J Gynaecol Obstet 1990, 32:215-222.

37. Quantin C, Sauleau E, Bolard P, Mousson C, Kerkri M, Brunet Lecomte P, et al: Modeling of high-cost patient distribution within renal failure diagnosis related group. J Clin Epidemiol 1999, 52:251-258.

38. McLachlan GJ, Peel D: Finite Mixture Models New York, Wiley 2000, chapters 2 and 6.

39. Australian Institute of Health and Welfare (AlHW): Gestational Diabetes Mellitus in Australia, 2005-06 Canberra, AlHW 2008 [http://www.aihw.gov.au/ publications/cvd/gdmia05-06/gdmia05-06.pdf], (Accessed November 28, 2009).

40. Hedderson M, Weiss N, Sacks D, Pettitt D, Selby J, Quesenberry C, et al: Pregnancy weight gain and risk of neonatal complications: macrosomia, hypoglycaemia, and hyperbilirubinemia. Obstet Gynecol 2006, 108:1153-1161.

41. Siega-Riz AM, Viswanathan M, Moos MK, Deierlein A, Mumford S, Knaack J, et al: A systematic review of outcomes of maternal weight gain according to the Institute of Medicine recommendations: birthweight, fetal growth, and postpartum weight retention. Am J Obstet Gynecol 2009, 201:339.e1-339.e14.

42. Mahony R, Foley M, McAuliffe F, O'Herlihy C: Maternal weight characteristics influence recurrence of fetal macrosomia in women with normal glucose tolerance. Aust N Z J Obstet Gynecol 2007, 47:399-401.

43. Ng SK, Krishnan T, McLachlan GJ: The EM algorithm. Handbook of Computational Statistics New York, Springer-VerlagGentle J, Hardle W, Mori Y 2004, 137-168

44. Ng SK, McLachlan GJ: An EM-based semi-parametric mixture model approach to the regression analysis of competing-risks data. Stat Med 2003, 22:1097-1111.

45. Kessler RC, Andrews G, Colpe AJ, Hiripi E, Mroczek DK, Normand SL, et al: Short screening scales to monitor population prevalences and trends in non-specific psychological distress. Psychol Med 2002, 32:959-976.

\section{Pre-publication history}

The pre-publication history for this paper can be accessed here: http://www.biomedcentral.com/1471-2458/10/460/prepub

\section{doi:10.1186/1471-2458-10-460}

Cite this article as: $\mathrm{Ng}$ et al:: Risk factors and obstetric complications of large for gestational age births with adjustments for community effects: results from a new cohort study. BMC Public Health 2010 10:460.

\section{Submit your next manuscript to BioMed Central and take full advantage of:}

- Convenient online submission

- Thorough peer review

- No space constraints or color figure charges

- Immediate publication on acceptance

- Inclusion in PubMed, CAS, Scopus and Google Scholar

- Research which is freely available for redistribution

Submit your manuscript at www.biomedcentral.com/submit
Biomed Centra 